\title{
BMJ Open Sociodemographic differences in women's experience of early labour care: a mixed methods study
}

Jane Henderson, Maggie Redshaw

To cite: Henderson J, Redshaw M. Sociodemographic differences in women's experience of early labour care: a mixed methods study. BMJ Open 2017;7:e016351. doi:10.1136/ bmjopen-2017-016351

- Prepublication history and additional material is available. To view please visi tthe journal (http://dx.doi.org/10.1136/ bmjopen-2016-014238).

Received 10 February 2017 Revised 5 April 2017 Accepted 7 April 2017
CrossMark

Nuffield Department of Population Health, Policy Research Unit in Maternal Health and Care, National Perinatal Epidemiology Unit, University of Oxford, Oxford, UK

Correspondence to Jane Henderson; jane. henderson@npeu.ox.ac.uk

\section{ABSTRACT}

Objectives To explore women's experiences of early labour care focusing on sociodemographic differences, and to examine the effect of antenatal education, using mixed methods.

Setting England, 2014.

Participants Women who completed postal questionnaires about their experience of maternity care, including questions about antenatal education, early labour and sociodemographic factors, included space for free-text comments.

Outcome measures Worries about labour, contact with midwives in early labour and subsequent care.

Methods This study was based on secondary analysis of a national maternity survey carried out in England in 2014. Quantitative data were analysed using descriptive statistics and binary logistic regression; qualitative data were analysed using a thematic content analytic approach. Results Completed questionnaires were received from 4578 women ( $47 \%$ response rate). There were significant differences by sociodemographic factors, particularly ethnicity, in women's worries about early labour. Compared with white women, women from black or minority ethnic groups had an adjusted OR of 1.93 (95\% Cl 1.56 to 2.39) of feeling worried about not knowing when labour would start. Among women who contacted a midwife at the start of labour, $84 \%$ perceived their advice as appropriate, more in older and multiparous women. Overall, $64 \%$ of women were asked to come to the hospital at this time, more in multiparous women (adjusted OR 1.63, 95\% Cl 1.35 to 1.96). Those who did not have access to antenatal education experienced greater worry about early labour. Five themes emerged from the qualitative analysis: 'Differentiating between early and active labour', 'Staff attitudes', 'Not being allowed...', 'Previous labours' and 'Perceived consequences for women'.

Conclusion These findings reinforce the importance of providing reassurance to women in early labour, taking care that women do not feel neglected or dismissed. In particular, primiparous and ethnic minority women reported greater worry about early labour and require additional reassurance.

\section{INTRODUCTION}

Early labour, also known as the latent phase, has been defined in a number of different ways but the National Institute for Health and Care Excellence defines it as a period
Strengths and limitations of this study

- Large study based on random sample of birth registrations in England.

- Both quantitative and qualitative data from women relating to early labour.

- Response rate of $47 \%$ makes generalisation difficult.

- Respondents, especially those who wrote free-text comments, predominantly primiparous, educated and resident in less deprived areas.

of time when there are painful contractions and some cervical changes. ${ }^{1}$ Early labour is usually a slow process during which women may feel distress and anxiety and lose confidence in their ability to cope. ${ }^{2}$ The resulting stress hormones may counter the effects of oxytocin and slow the progress of labour ${ }^{3}$ resulting in further anxiety and distress.

Many observational studies have noted that admission to hospital prior to active labour increases the risk of oxytocin augmentation, epidural analgesia and caesarean section. ${ }^{4-9}$ Health professionals, therefore, strongly recommend to women that they stay home as long as possible, until contractions are as frequent as three in $10 \mathrm{~min}$. This cut-off is based on a graphic approach developed by Friedman in the $1950 \mathrm{~s} .{ }^{10}$ However, for women, the negative effects of staying at home in pain include confusion, anger, resentment and feeling neglected, unsupported and anxious. ${ }^{2}$ It has been estimated that between $30 \%$ and $45 \%$ of women are admitted to hospital prior to active labour. ${ }^{11} 12$

A randomised trial of an intervention providing additional support to women at home during early labour resulted in more admissions in active labour, reduced use of analgesia, reduced neonatal morbidity and increased maternal satisfaction although emotional well-being and distress did not differ between the groups. ${ }^{12}$ Other studies have found no significant benefit associated with structured care involving one-to-one 
care, positioning techniques and positive imagery in early labour, ${ }^{13}$ or use of an algorithm for defining active labour based on presence of painful, regular, moderate or strong contractions and either cervical effacement and dilation of at least $3 \mathrm{~cm}$, spontaneous rupture of membranes or a 'show'. ${ }^{14}$

Several studies have used qualitative techniques to examine women's views and experience of care in early labour. ${ }^{15-18}$ The findings of these studies reflect women's uncertainty and anxiety about presenting at the hospital at the right time, worry about being sent home if they arrive too early, their need for validation, the pressure as well as support provided by friends and family, surprise and consternation regarding the intensity of pain in early labour and fatigue resulting in reduced ability to cope. Other qualitative studies have examined the care of women in early labour from the midwives' perspective. ${ }^{192}$ These stress the importance of providing reassurance to the woman and her family and normalising the situation. However, they differed in overall paradigm which may reflect differences in the organisation of care in Norway and the UK. The Norwegian study ${ }^{19}$ acknowledged that some women labour quickly and clinical judgement on the phone is necessarily limited. These midwives believed that it was best for women to come to the hospital for assessment if they wished and then to feel sufficiently informed and empowered to make the decision to return home if they were not in active labour. In contrast, the midwives in the UK study ${ }^{20}$ stressed the importance of the midwives' role as 'gatekeeper' acknowledging that they had different priorities from the women. They reported that they could tell from a woman's voice, or through intuition, whether she was in active labour. Moreover, some midwives used trivialising language to describe women in early labour such as 'frequent flyers'. They acknowledged that although labour ward workload should not take precedence over women's experience, it often did. ${ }^{20}$

Only one study used quantitative techniques to explore women's experience of early labour. ${ }^{17}$ They reported that $46 \%$ of women were aware of the expectation that they would stay at home during early labour, and that being made to feel unwelcome and not being treated with respect or as an individual were associated with feeling dissatisfied with care in early labour. This was exacerbated if they were sent home more than once without follow-up arrangements being made, or if they felt discouraged from returning, especially if they felt that this was due to the unit being busy rather than it being clinically appropriate.

No studies have examined the early labour experiences of women from different sociodemographic groups although evidence from other areas suggests that women from more disadvantaged groups have poorer experience of maternity care. ${ }^{21-26}$ The aims of this study were therefore (1) to explore the experiences of early labour care, both quantitatively and qualitatively, among women with different sociodemographic characteristics, and (2) to determine whether women who attended antenatal education were less worried about early labour and less likely to go to the hospital early.

\section{METHODS}

This study involved secondary analysis of a national maternity survey carried out in England in 2014. ${ }^{27}$ Ten thousand women were randomly selected from birth registration statistics by the staff at the Office for National Statistics (ONS) excluding those aged less than 16 years and those whose baby had died. The questionnaire, together with a letter, information leaflet and a sheet with a single sentence in 18 non-English languages (providing a Freephone number for an interpreter), encouraged women to complete the questionnaire and return it in a Freepost envelope. These were sent to women at 3 months postpartum. The questionnaire could also be completed online. Using a tailored reminder system, up to three reminders were sent as required.

A mixed methods design was used with the questionnaire including both closed and open questions. Women were asked about their experience of maternity care including early labour, and also asked questions about sociodemographic characteristics and whether they attended antenatal classes. Using a validated worries checklist, they were asked a range of questions, including if, before labour started, they were worried about not knowing when they would go into labour and about getting to the hospital in time (answer options: very, quite, not very, not at all worried). ${ }^{28}$ Women who had a labour were asked if they contacted a midwife or the hospital at the very start of their labour and, if so, whether they felt that they were given appropriate advice and support. If they had contacted a midwife or the hospital, they were asked about the response, that is, whether they were asked to come to the hospital, stay at home, wait and phone again or phone again if worried. We have considered this as early labour care although we acknowledge that it may have also included women in active labour. All data were necessarily based on women's perception and recall of events.

There was space for free-text comment at the point in the questionnaire relating to early labour and at the end. Women were also asked what they would like to tell other women about having a baby in that hospital or unit. These free-text comments were the sole source of qualitative data.

ONS provided information about each woman's age group, country of birth, marital status and an area-based measure, the Index of Multiple Deprivation (IMD) in quintiles, which enabled comparison of responders and non-responders. In this study, IMD, ethnicity (white vs black or minority ethnic group (BME)), maternal age in six categories and parity (primiparous vs multiparous) were included as sociodemographic variables. Women who had an induction of labour or caesarean planned and carried out before labour were excluded from the analysis. 
A descriptive analysis was carried out using raw percentages to establish how sociodemographic groups' experiences differed in their worries about early labour, whether they contacted a healthcare professional in early labour and received appropriate advice. Differences were tested using the $\chi^{2}$ statistic. As there was likely to be an overlap between different sociodemographic factors, binary logistic regression was used to estimate the extent of this to determine the main drivers for any differences seen and to test the effect of antenatal education. Binary logistic regressions were adjusted for each of the sociodemographic variables. All quantitative analyses were carried out in Stata V.13.

Free-text responses to the questions relating to care in early labour, what they would like to tell other women, and at the end of the questionnaire were analysed following the method of Garcia et al..$^{29}$ Responses were filtered using the keywords 'early', 'latent', 'sent home', 'come/came back' and 'return' then read and selected if they referred to early labour. Comments were read and coded in an iterative process by both authors, coding themes as they arose using a thematic content analytic approach. Where differences in interpretation arose, these were resolved by discussion and reference to the raw data. Deviant cases were sought and triangulation with quantitative data on satisfaction was used to test the credibility and trustworthiness of the findings. ${ }^{30}$

Ethical approval for the survey was obtained from the NRES (the National Research Ethics Service) Committee for Yorkshire and The Humber-Humber Bridge (Research Ethics Committee reference 14/YH/0065). Written informed consent from participants was not considered necessary; consent was implicit in completion and return of the questionnaire.

\section{RESULTS}

Completed questionnaires were received from 4578 women representing a $47 \%$ usable response rate. Of these, 398 had a planned caesarean section carried out before labour had started, and 1081 had an induction of labour. These were excluded from the analyses, leaving 3099 women. These were $49 \%$ primiparous, $83 \%$ white and $42 \%$ aged 30 years or more. Compared with non-respondents, women who completed the questionnaire were significantly more likely to be older, married, living in a less deprived area and born in the UK. ${ }^{27}$

\section{Quantitative results}

The descriptive statistics shown in table 1 indicate considerable differences in women's worries about early labour and in their care at this time. Worry about knowing when labour would start was significantly greater in primiparous women and those from BME groups. Worry about getting to hospital in time was significantly greater in multiparous women and, again, those from BME groups.

Overall, $88 \%$ of women contacted a midwife or the hospital at the start of labour (table 2). This was significantly less likely in women aged 40 years or more and in multiparous women. Overall, $84 \%$ of women reported receiving appropriate advice at this time, with significantly more reporting this among older and multiparous women. Women were more likely to consider the advice appropriate if it included coming to the hospital (figure 1). Overall, two-thirds of women were eventually asked to come to the hospital to be assessed, but $48 \%$ were at some point asked to stay at home and phone again later. This latter was significantly more common in primiparous women (table 3 ).

A series of binary logistic regressions was undertaken to understand the most important factors in the associations between sociodemographic variables and perceptions of early labour care (tables 4 and 5). These confirmed the importance of parity and ethnicity for worries about going into labour, and suggested that, when adjusted for other variables, women aged 20-24 years experienced greater worry about not knowing when labour would start. Multiparous women and those aged 40 years or more were significantly less likely to contact a healthcare professional; and women aged 20-24 years were significantly less likely to feel that they had received appropriate advice (table 5). Parity and, marginally, residence in an area of deprivation remained associated with being asked to come to the hospital (sometimes after being asked to wait or phone back later) after adjustment for the other sociodemographic factors.

\section{Antenatal education}

In the UK, women are given information and a registration form for antenatal classes at the time of booking. However, there has been a substantial decline in National Health Service (NHS) (free) provision of antenatal classes. ${ }^{31}$ It was postulated that worry about labour might be reduced in women who had attended antenatal education. Half of primiparous and only $9 \%$ of multiparous women attended NHS antenatal classes; a further 23\% of primiparous and 5\% of multiparous women attended non-NHS classes for which they paid. For primiparous women only, there was a strong association between being unable to attend NHS classes, either because they were not offered or because they were booked up, and feeling 'very worried' about not knowing when labour would start (but not about getting to the hospital in time). After adjustment for age, ethnicity and IMD, women who did not have access to antenatal classes had an OR of 1.58 (95\% CI 1.10 to 2.25 ) of being very worried about not knowing when labour would start. BME women were significantly less likely to attend antenatal classes due to not being offered them or them being booked up. However, those BME women who did attend classes were no less likely to be worried about these aspects of early labour. These data are shown in online supplementary data.

\section{Qualitative results}

Fifty-nine women wrote free-text comments relating to early labour. Table 6 shows the characteristics of these 
Table 1 Sociodemographic characteristics of women with worries about early labour

\begin{tabular}{|c|c|c|c|c|}
\hline & \multicolumn{2}{|c|}{$\begin{array}{l}\text { Worry about knowing when labour would start } \\
\text { (Missing=106) }\end{array}$} & \multicolumn{2}{|c|}{$\begin{array}{l}\text { Worry about getting to hospital in time } \\
\text { (Missing=112) }\end{array}$} \\
\hline & Very/quite worried & Not very/at all worried & Very/quite worried & Not very/at all worried \\
\hline & n (\%) & n (\%) & n (\%) & n (\%) \\
\hline \multicolumn{5}{|l|}{ Maternal age (years) } \\
\hline$<20$ & $40(51.9)$ & $37(48.1)$ & $54(69.2)$ & $24(30.8)$ \\
\hline $20-24$ & $159(46.2)$ & $185(53.8)$ & $209(60.6)$ & $136(39.4)$ \\
\hline $25-29$ & $441(53.3)$ & $386(46.7)$ & $510(61.6)$ & $318(38.4)$ \\
\hline $30-34$ & $579(54.0)$ & $494(46.0)$ & $673(62.9)$ & $397(37.1)$ \\
\hline $35-39$ & 298 (53.2) & $262(46.8)$ & $338(61.1)$ & 215 (38.9) \\
\hline $40+$ & $61(55.0)$ & $50(45.0)$ & $71(63.4)$ & $41(36.6)$ \\
\hline Total & $1578(52.7)$ & $1414(47.3)$ & $1855(62.1)$ & $1131(37.9)$ \\
\hline \multicolumn{5}{|l|}{ Missing $=1$} \\
\hline \multicolumn{5}{|l|}{ Parity } \\
\hline Primiparous & 713 (49.3) & $733(50.7)$ & $944(65.4)$ & 499 (34.6) \\
\hline Multiparous & $834(56.7)$ & $637(43.3)$ & $866(59.1)$ & $600(40.9)$ \\
\hline Total & $1547(53.0)$ & $1370(47.0)^{\star \star \star}$ & $1810(62.2)$ & $1099(37.8)^{\star \star \star}$ \\
\hline \multicolumn{5}{|l|}{ Missing=104 } \\
\hline \multicolumn{5}{|c|}{ Index of multiple deprivation (quintiles) } \\
\hline 1 (least deprived) & $322(55.0)$ & $263(45.0)$ & $370(63.4)$ & $214(36.6)$ \\
\hline 2 & $315(54.1)$ & $267(45.9)$ & $367(62.8)$ & 217 (37.2) \\
\hline 3 & $329(53.8)$ & $282(46.2)$ & $381(62.7)$ & $227(37.3)$ \\
\hline 4 & 317 (49.3) & $326(50.7)$ & $389(60.6)$ & $253(39.4)$ \\
\hline 5 (most deprived) & $296(51.8)$ & $275(48.2)$ & $348(61.3)$ & $220(38.7)$ \\
\hline Total & $1579(52.8)$ & $1413(47.2)$ & $1855(62.1)$ & $1131(37.9)$ \\
\hline \multicolumn{5}{|l|}{ Missing $=1$} \\
\hline \multicolumn{5}{|c|}{ Black or minority ethnic group } \\
\hline No & $1341(55.0)$ & $1098(45.0)$ & 1557 (63.7) & 886 (36.3) \\
\hline Yes & $195(41.0)$ & $281(59.0)$ & $251(53.3)$ & $220(46.7)$ \\
\hline Total & $1536(52.7)$ & $1379(47.3)^{\star \star \star}$ & $1808(62.0)$ & $1106(38.0)^{\star \star \star}$ \\
\hline Missing=109 & & & & \\
\hline
\end{tabular}

${ }^{*} \mathrm{p}<0.05,{ }^{* \star} \mathrm{p}<0.01,{ }^{* \star *} \mathrm{p}<0.001$.

women compared with survey respondents overall. They were disproportionately older, primiparous, more educated and resident in the least deprived quintiles but none of the differences was statistically significant. Table 7 shows the main themes that arose from the free-text comments relating to early labour. These were 'Differentiating between early and active labour', 'Staff attitudes', 'Not being allowed...', 'Previous labours' and 'Perceived consequences for women'. Individual quotations are used to illustrate these themes.

\section{Differentiating between early and active labour}

Women understood that to be credible and viewed by midwives as genuinely in labour, they had to meet certain criteria regarding frequency and duration of contractions. However, not all women in active labour met these criteria:
Contractions started on a Weds, had the baby on a Saturday. Kept ringing the maternity ward to be told not to come in until I was 3-10-1 (3 contractions in $10 \mathrm{~min}$, lasting $1 \mathrm{~min}$ each). That isn't going to apply to everyone and [one] should be invited into hospital. [Primip, IMD1, 25-29 years, white]

Went into hospital in labour $3 \mathrm{~min}$ contractions and sent home again as only $1.5 \mathrm{~cm}$ dilated - less than 2 hours later I gave birth, crowning in the hospital car park, head out in the elevator. This was very traumatic and wish they allowed me to stay instead of stranding me at home. [Primip, IMD5, 30-34years, white]

Women also reported that midwives judged from their voice and behaviour whether they were in active labour. Some women therefore deliberately 'acted' the part: 
Table 2 Sociodemographic characteristics of women contacting a health professional at the start of labour

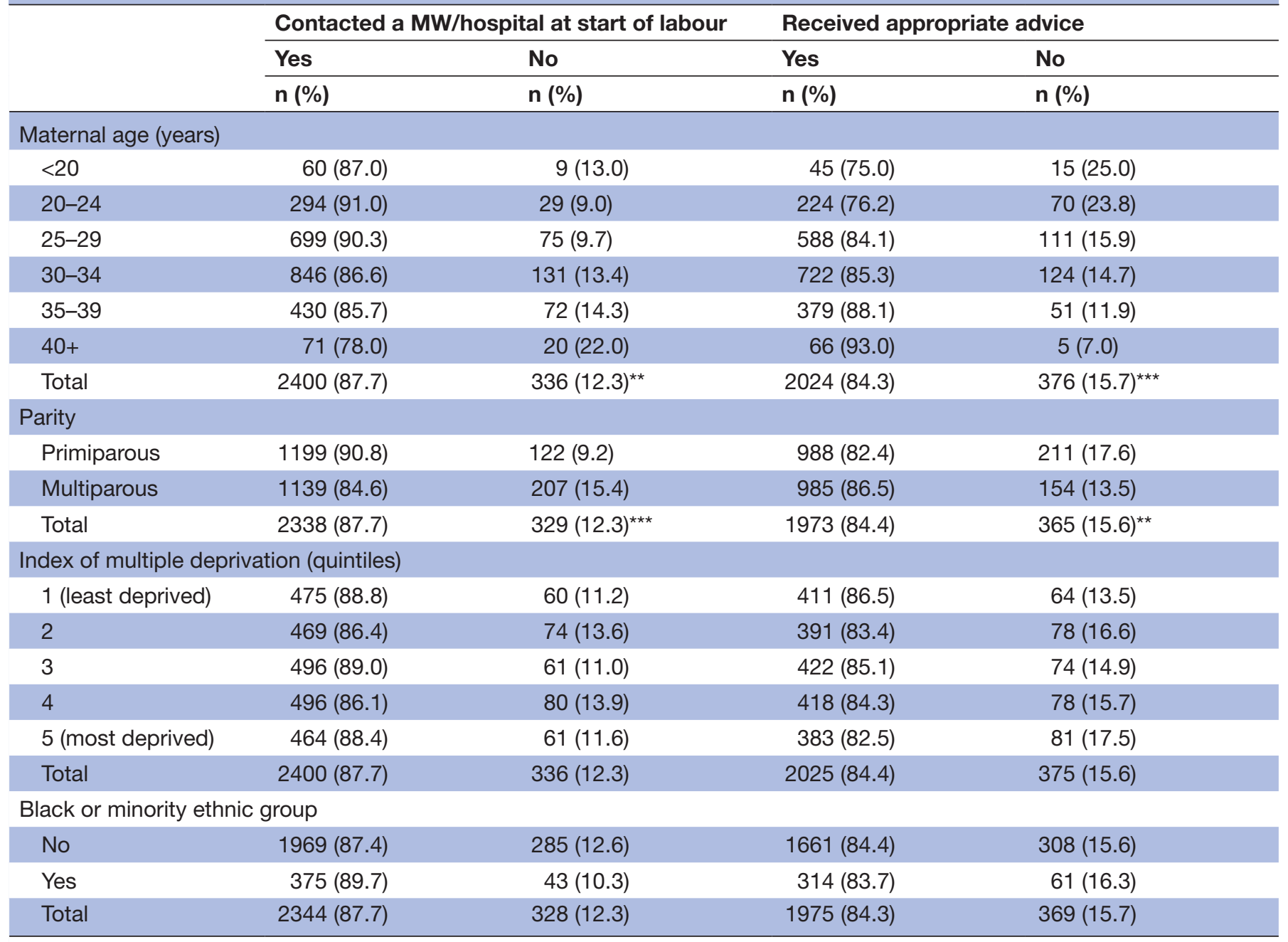

${ }^{*} \mathrm{p}<0.05,{ }^{* \star} \mathrm{p}<0.01,{ }^{* * *} \mathrm{p}<0.001$.

MW, midwife.

When we went into labour with this baby, I phoned the hospital twice and both times they said I didn't sound like I was in labour and suggested I stay at home, [...] They made us feel a bit silly for coming into hospital, as I wasn't 'screaming and shouting', they assumed I was only in early labour. [Multip, IMD3, 35-39years, white]

[...] After my husband lied to the hospital about the time between contractions I was eventually told to come in. Although my waters hadn't broken I was already $6 \mathrm{~cm}$ dilated. [Primip, IMD2, 30-34years, white]

\section{Staff attitudes}

Many women perceived negative staff attitudes both on the phone and when attending the unit for assessment. Women were made to feel foolish by midwives who were insensitive, rude, abrupt and dismissive:

[...] I had to scream/cry down the phone before she abruptly told me 'you better come in then' not a pleasant experience. [Multip, IMD3, 30-34years, white]

Another common subtheme was women feeling vindicated, the midwife having assumed that they were not in active labour, but on examination, they were close to full dilatation:

I knew I was further along than they assumed and insisted on an exam where they discovered I was $6 \mathrm{~cm}$ and baby came 3 hours later! [Multip, IMD3, 35-39years, white]

Eventually I rang back to say I want to come in to be checked over only to be told 'well you will probably end up going home anyway'. [...] Would like to point out when arrived at hospital when I was checked over I was $9 \mathrm{~cm}$. [Primip, IMD1, 25-29years, white]

Not being allowed...

Women reported not being allowed to come to the hospital, not being allowed to stay and, in a few cases, having to beg for a vaginal examination. This made them 


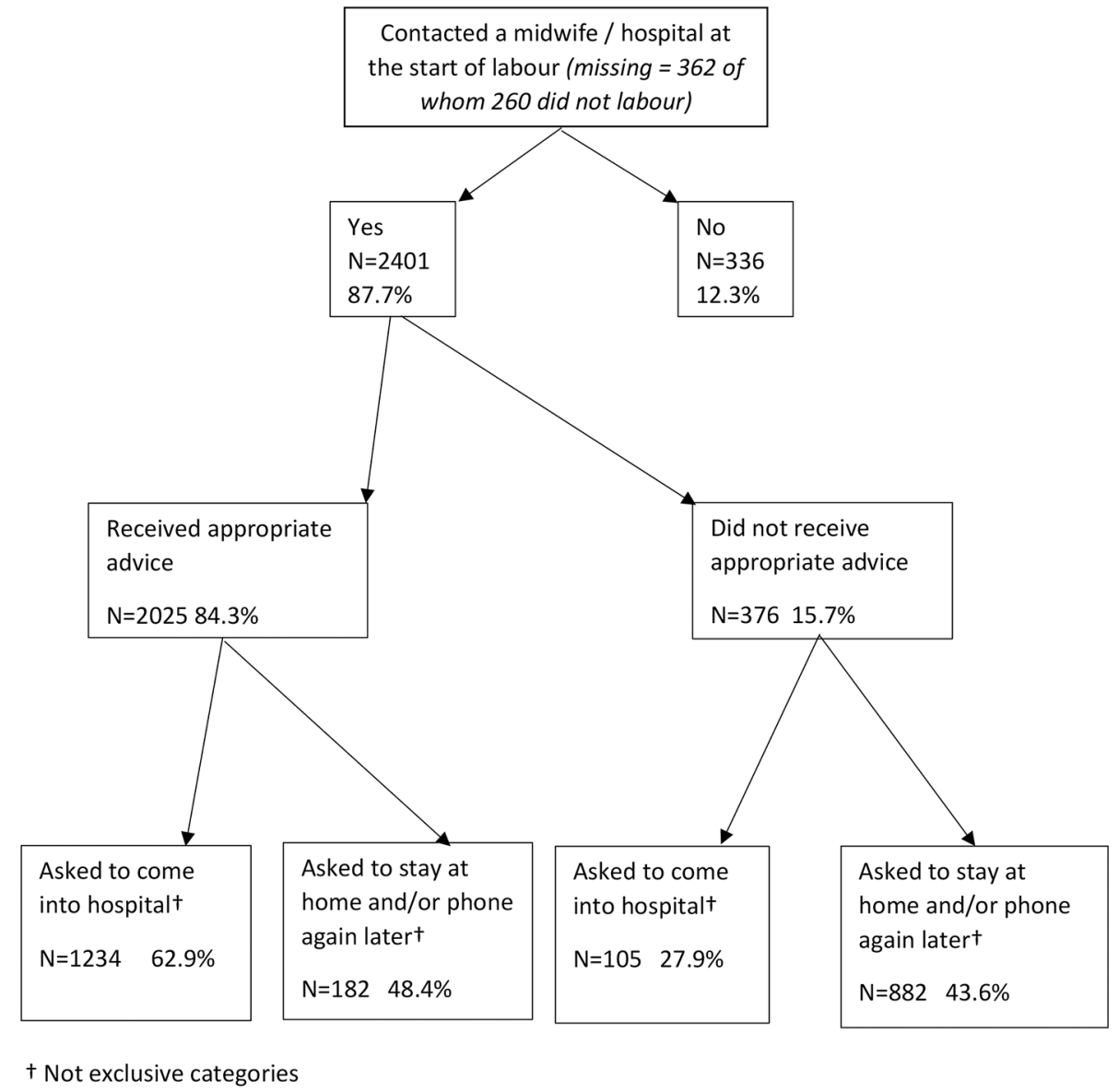

Figure 1 Numbers and proportions of women contacting midwife or hospital at the start of labour and resulting care (of the 3099 women who had neither induction of labour nor a planned caesarean section before the start of labour).

more anxious as they felt that the hospital was a safer place than home:

Labour was slow so kept getting told to stay at homethat was very distressing and made me more anxious. [Primip, IMD3, 25-29 years, BME]

Crying out in pain and begging for midwife to check over/do internal to see how dilated. Only then discovered $6 / 7 \mathrm{~cm}$ dilated and wheeled in wheelchair to labour ward. [Primip, IMD1, 25-29years, white]

In addition, some women reported that the staff did not take account of their travel time, necessitating several lengthy and uncomfortable journeys:

My waters broke $11.30 \mathrm{pm}$ - phoned hospital told to go in [...] Got told to go home as it was my 1 st baby - told to look out for contractions [...] by 7am I was in pain - phoned hospital told to go back in - my 3rd 40 min journey - when I got to hospital - got told I was in the very early stages of labour - not checked at all and got told to go home [...] Got home - another $40 \mathrm{~min}$ journey. Started bleeding was being sick and in pain - phone hospital again and got told to go back AGAIN [...] When I got to the hospital, I couldn't walk $[\ldots]$ Got to the labour ward on the sixth floor
- told I was fully dilated and the head was there [...] [Primip, IMD3, 35-39 years, white]

The above quote also illustrates a subtheme of 'Not being checked' which was reported by several women and was associated with delay in diagnosis of active labour and inappropriate management:

[...] labour started naturally at $1 \mathrm{am}$. I informed the midwife at 5am but she refused to believe I was in established labour. By the time I convinced her to check me at 7:45am, I was $9 \mathrm{~cm}$ dilated and baby was born within next ten mins. The lesson to be learnt is that some midwives will only take you seriously if you are screaming in pain. [Multip, IMD4, 25-29years, ethnicity missing]

\section{Previous labours}

Some midwives were reportedly unwilling to take account of parity in assessing whether a woman was in early or active labour. Primiparous women clearly need more support and reassurance:

Being my first pregnancy when I went into labour I was unsure. [...] I feel for first time mums - a little more understanding at the hospital that we don't 
Table 3 If midwife or hospital contacted in early labour, woman asked to come in or stay home

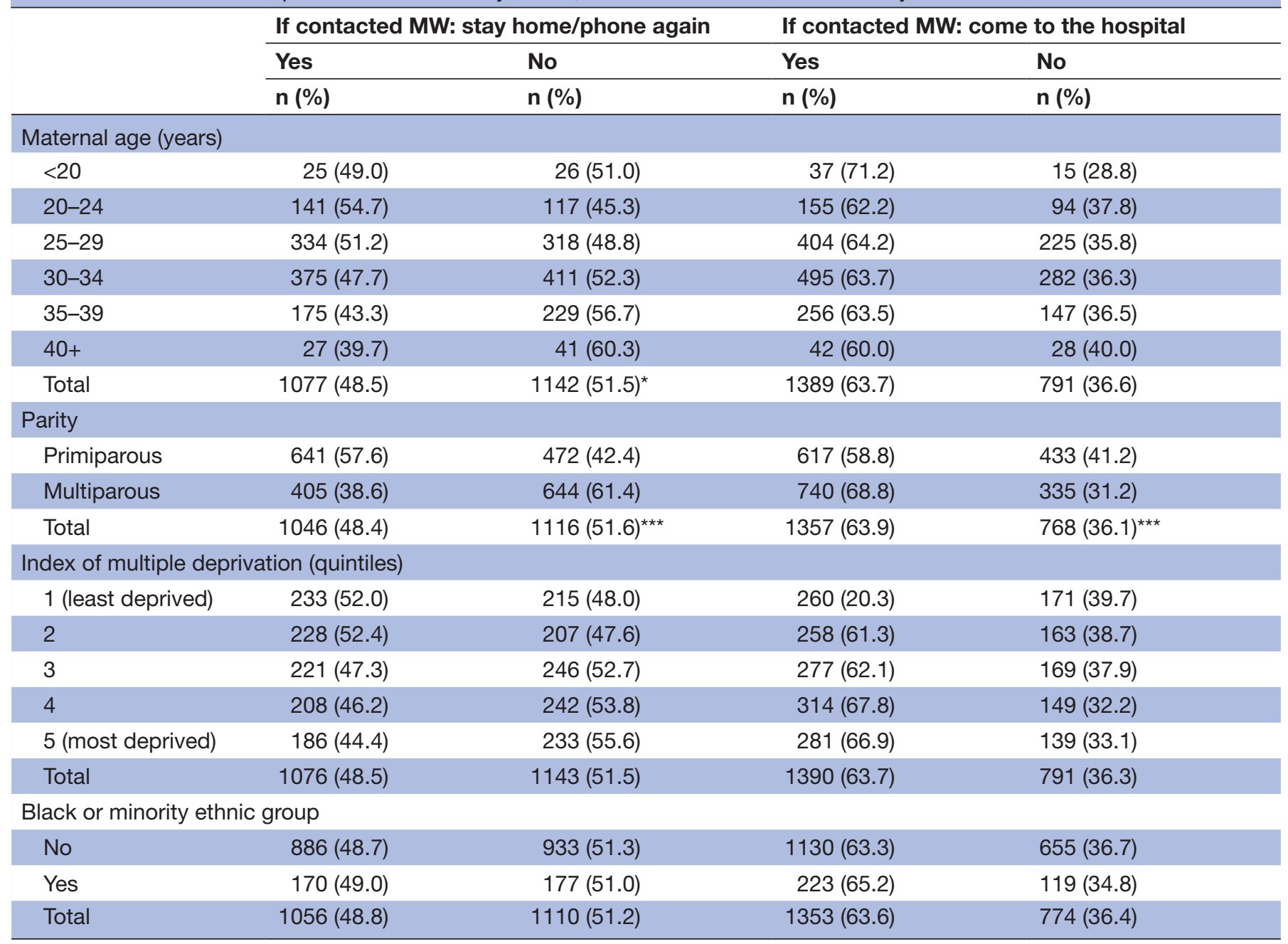

${ }^{*} \mathrm{p}<0.05,{ }^{* \star} \mathrm{p}<0.01,{ }^{* * *} \mathrm{p}<0.001$.

MW, midwife.

know what our bodies are doing would help. [Primip, IMD2, 30-34years, white]

Multiparous women who had experienced labour before are likely to recognise the different stages and sometimes reported not being listened to. Advice to other women included 'you know your body' and 'trust your instincts'.

[...] My husband was told to leave and I was transferred to a ward. I was still having contractions but told it would be ages until active labour. I explained my contractions were always irregular but once pain increased the 2nd stage would be very quick [...] My husband was still told to go home. After he left I started having more painful contractions and called for the midwife. She checked me and thought active labour had started and went to call the labour ward. I had to call her back 5 min later as I needed to start pushing. I called my husband but he did not get there in time. It was a very scary experience as there was no equipment in the room to deliver the baby (as it was a normal antenatal ward) [...] [Multip, IMD3, 30-34 years, BME]

When I went into labour with my 3rd child I called the labour ward and wanted to come into hospital but they wouldn't let me. I didn't feel like she was listening to me even though I said I labour quickly. By the time I got to hospital I was in too much pain to have IV's [for Group B strep]. If I'd gone into hospital when I wanted to then I would have had pain relief sooner and would have received the antibiotics. [Multip, IMD5, 35-39years, white]

\section{Perceived consequences for women}

Many of the women who had felt let down by the staff in early labour, having to stay at home when they wanted to be in the hospital, went on to report a failure to get appropriate pain relief and medication (as in the previous quote), a rushed, sometimes operative, delivery, feelings of shock and delayed attachment to their baby: 
Table 4 Binary logistic regression showing effects of sociodemographic factors on worries about going into labour, each variable adjusted for all others

\begin{tabular}{|c|c|c|}
\hline & $\begin{array}{l}\text { Very/quite worried } \\
\text { about not knowing } \\
\text { when labour } \\
\text { would start }\end{array}$ & $\begin{array}{l}\text { Very/quite worried } \\
\text { about getting to } \\
\text { the hospital in } \\
\text { time }\end{array}$ \\
\hline & OR $(95 \% \mathrm{Cl})$ & OR $(95 \% \mathrm{Cl})$ \\
\hline \multicolumn{3}{|l|}{$\begin{array}{l}\text { Maternal age } \\
\text { (years) }\end{array}$} \\
\hline$<20$ & 0.98 (0.60 to 1.61$)$ & 0.78 (0.46 to 1.35$)$ \\
\hline $20-24$ & 1.41 (1.09 to 1.83$)$ & $1.20(0.92$ to 1.57$)$ \\
\hline $25-29$ & $0.96(0.79$ to 1.16$)$ & 1.10 (0.90 to 1.33$)$ \\
\hline 30-34 & 1.00 & 1.00 \\
\hline 35-39 & 1.08 (0.88 to 1.34$)$ & $1.05(0.85$ to 1.31$)$ \\
\hline $40+$ & $0.91(0.61$ to 1.37$)$ & 0.89 (0.59 to 1.35$)$ \\
\hline \multicolumn{3}{|l|}{ Parity } \\
\hline Primiparous & 1.00 & 1.00 \\
\hline Multiparous & 0.72 (0.62 to 0.84$)$ & 1.30 (1.11 to 1.52$)$ \\
\hline \multicolumn{3}{|l|}{$\begin{array}{l}\text { Index of multiple } \\
\text { deprivation }\end{array}$} \\
\hline 1 (least deprived) & 1.00 & 1.00 \\
\hline 2 & 0.94 (0.74 to 1.19$)$ & 0.96 (0.75 to 1.23$)$ \\
\hline 3 & 0.98 (0.77 to 1.24$)$ & 1.01 (0.80 to 1.29$)$ \\
\hline 4 & 1.13 (0.89 to 1.42$)$ & 1.00 (0.78 to 1.27$)$ \\
\hline 5 (most deprived) & 0.91 (0.71 to 1.17$)$ & $0.92(0.71$ to 1.19$)$ \\
\hline \multicolumn{3}{|l|}{ Ethnicity } \\
\hline White & 1.00 & 1.00 \\
\hline BME & 1.93 (1.56 to 2.39$)$ & 1.56 (1.26 to 1.92$)$ \\
\hline
\end{tabular}

BME, black or minority ethnic group.

My labour was a bit stop-start and the unit suggested I didn't come in until the contractions were every 3 mins and at least $1 \mathrm{~min}$ in duration. I don't feel this was the right advice for me and regret not going to get checked out as I think if I had gone in after my contractions were about $5 \mathrm{~min}$, I may have had a natural birth rather than C-section. However, the care I received was excellent other than that. [Primip, IMD2, 25-29years, white]

[...] My baby's head was already out by the time the midwife arrived in the room. I had to have my baby standing up as there was not time to get on the bed. I was in complete shock when my baby was born due to this and I did not feel the immediate rush of love for my baby because I was in too much shock and pain.

[Multip, IMD3, 30-34years, white]

Some women ascribed their poor experiences to staff shortages or the facilities being particularly busy:

They [staff] were horribly rushed, kept saying things would happen that didn't happen, didn't pass information between colleagues, and didn't give us consistent information. It was clear that they were horribly overworked and were dealing with people in more priority than me. I feel confident that I would have got more attention had I been higher priority (I wasn't at risk) but it was an unpleasant experience where I felt powerless and confused for a lot of the time ... [Primip, IMD2, 30-34years, white]

All the free-text comments relating to early labour were negative so it was not possible to estimate the association between qualitative comments and the quantitative measure of satisfaction with care during labour and birth. However, among women who wrote a free-text comment relating to early labour, only $32.1 \%$ were very satisfied with their care at this time compared with $62.8 \%$ in the whole sample. The proportions who were very dissatisfied were $7.1 \%$ and $2.3 \%$, respectively. Similarly, while $84 \%$ of women overall felt that they received appropriate advice when they phoned a midwife in early labour, only $36 \%$ of women who wrote free-text comments considered the advice appropriate.

\section{DISCUSSION}

The findings of this study suggest that there is considerable variation in women's experience of early labour by sociodemographic characteristics. Although the differences by parity are to be expected, the significantly increased worry among BME women is more surprising. However, it confirms the findings of a previous study which found that ethnic minority women were more likely to report high levels of worry about almost all aspects of birth, irrespective of parity and residence in an area of deprivation. ${ }^{32}$ After adjusting for parity, ethnicity and IMD, women aged 20-24 years were also more likely to be worried about not knowing when labour would start and, again, this is consistent with earlier research. ${ }^{22}$ Women in this age group were also significantly less likely to feel that they received appropriate advice when they phoned a midwife or the hospital. This may reflect a perception in this group that they are viewed as problematic and immature by healthcare professionals. ${ }^{33}$

Primiparous women who were not able to attend NHS antenatal classes, either because they were not offered or because they were booked up, were significantly more likely to be very worried about not knowing when labour would start. This finding persisted after adjustment for sociodemographic characteristics. This is consistent with the findings of a Danish randomised controlled trial which found that antenatal education in small groups increased women's confidence in their ability to cope at home during labour. ${ }^{34}$ However, the women who were unable to access NHS antenatal education in the current study were also significantly less likely to have planned their pregnancy or to have booked before 10 weeks. Thus, they may have been more worried generally.

The free-text comments relating to women's experience of early labour were entirely negative. This partly reflects the propensity for respondents to write 
Table 5 Binary logistic regression showing combined effects of sociodemographic factors on experience of contacting midwife or hospital in early labour

\begin{tabular}{|c|c|c|c|}
\hline & $\begin{array}{l}\text { Contacted HCP at start of } \\
\text { labour }\end{array}$ & Received appropriate advice & $\begin{array}{l}\text { Asked to come to the } \\
\text { hospital }\end{array}$ \\
\hline & OR $(95 \% \mathrm{Cl})$ & OR $(95 \% \mathrm{Cl})$ & OR $(95 \% \mathrm{Cl})$ \\
\hline \multicolumn{4}{|l|}{ Maternal age (years) } \\
\hline$<20$ & 0.87 (0.39 to 1.90$)$ & 0.55 (0.28 to 1.05$)$ & 1.51 (0.79 to 2.86$)$ \\
\hline $20-24$ & 1.40 (0.90 to 2.19$)$ & $0.57(0.40$ to 0.81$)$ & 0.95 (0.70 to 1.30$)$ \\
\hline $25-29$ & 1.27 (0.93 to 1.73$)$ & 0.87 (0.65 to 1.16$)$ & $1.08(0.86$ to 1.35$)$ \\
\hline $30-34$ & 1.00 & 1.00 & 1.00 \\
\hline $35-39$ & 0.97 (0.71 to 1.34$)$ & $1.17(0.82$ to 1.67$)$ & $0.93(0.72$ to 1.21$)$ \\
\hline $40+$ & $0.56(0.33$ to 0.96$)$ & 2.70 (0.96 to 7.58$)$ & $0.77(0.47$ to 1.28$)$ \\
\hline \multicolumn{4}{|l|}{ Parity } \\
\hline Primiparous & 1.00 & 1.00 & 1.00 \\
\hline Multiparous & 0.59 (0.46 to 0.75$)$ & 1.24 (0.98 to 1.58$)$ & 1.63 (1.35 to 1.96$)$ \\
\hline \multicolumn{4}{|l|}{ IMD } \\
\hline 1 (least deprived) & 1.00 & 1.00 & 1.00 \\
\hline 2 & 0.75 (0.52 to 1.09$)$ & 0.84 (0.58 to 1.21$)$ & 1.09 (0.82 to 1.45$)$ \\
\hline 3 & 0.95 (0.65 to 1.39$)$ & 0.99 (0.68 to 1.43$)$ & $1.11(0.84$ to 1.47$)$ \\
\hline 4 & 0.70 (0.49 to 1.02$)$ & 0.95 (0.66 to 1.38$)$ & 1.34 (1.01 to 1.79$)$ \\
\hline 5 (most deprived) & 0.91 (0.60 to 1.36$)$ & 0.88 (0.60 to 1.29$)$ & $1.23(0.91$ to 1.66$)$ \\
\hline \multicolumn{4}{|l|}{ Ethnicity } \\
\hline White & 1.00 & 1.00 & 1.00 \\
\hline BME & 1.39 (0.98 to 1.99$)$ & 0.89 (0.65 to 1.23$)$ & $1.00(0.77$ to 1.29$)$ \\
\hline
\end{tabular}

BME, black and minority ethnic group; HCP, healthcare professional; IMD, Index of Multiple Deprivation.

additional comments when they have an issue about which they would like to comment or complain. ${ }^{29}$ To put it into context, over three-quarters of women contacting a midwife or hospital at the start of labour reported receiving appropriate advice but the corresponding proportion for women who wrote free-text responses on this topic was just over a third. The main themes related to women's perceptions of staff assumptions and attitudes and not being allowed to come to hospital or stay, and these resonate strongly with earlier studies..$^{216-18} 2035$ In particular, the study by Spiby $e t a l^{20}$ used focus groups to understand the views of UK midwives dealing with women in early labour. They found that some midwives held negative perceptions and stereotypes of women and labelled them accordingly. Studies which analysed this subject from women's perspectives underscored the importance to women of arriving at the hospital at the 'right time', the distress associated with being sent home and the impact of having a caring or uncaring midwife, of being believed. ${ }^{216}$ The neglect felt by some women at this time echoes the results of a study of women's experience of the early phase of induction of labour. ${ }^{36}$

The other two themes that arose in this study related to parity and the perceived consequences for women of poor early labour care. Parity is not mentioned in the literature although some studies only included primiparous women. ${ }^{12} 141718$ In this study, the issues facing primiparous and multiparous women differed: primiparous women wanted more support and reassurance whereas multiparous women, having already experienced labour, remembered how it felt and were sometimes angry at not being believed. Some women perceived negative consequences resulting from inaccurate diagnosis of labour. These included a lack of time for pain relief, medication and a perception of delayed attachment to their baby, and also women who thought that an operative delivery may have been avoided had early labour been better managed. Although this latter outcome has been demonstrated to result from admission in early labour, ${ }^{12}$ no qualitative studies have reported on this.

A strength of this study is that it was based on a large random sample of births in England and uses both quantitative and qualitative data from the same primiparous and multiparous women. Limitations include the $47 \%$ response rate with under-representation of young women, those born outside the UK and women residents in deprived areas. ${ }^{27}$ However, $16 \%$ of respondents were BME, $17 \%$ left full-time education aged 16 years or less, $20 \%$ were residents in the most deprived quintile and $13 \%$ did not have a partner at the time of the survey. Similarly, the free-text comments were disproportionately from primiparous, more educated women 
Table 6 Sociodemographic characteristics of women who wrote free-text comments relating to early labour compared with all respondents

\begin{tabular}{ll}
$\begin{array}{l}\text { Women who wrote free-text } \\
\text { comments relating to early labour }\end{array}$ & $\begin{array}{l}\text { All women who completed the } \\
\text { questionnaire }\end{array}$ \\
\hline $\mathrm{n}(\%)$ & $\mathrm{n}(\%)$
\end{tabular}

\begin{tabular}{|ccc|}
\hline Maternal age (years) & & \\
\hline $16-24$ & $7(11.9)$ & $280(14.0)$ \\
\hline $25-34$ & $22(37.3)$ & $1118(24.2)$ \\
\hline 35 or more & $30(50.8)$ & $4576(100)$ \\
\hline Total & $59(100)$ & \\
\hline Parity & & $2207(49.8)$ \\
\hline Primiparous & $32(56.1)$ & $2223(50.2)$ \\
\hline Multiparous & $25(43.9)$ & $4430(100)$ \\
\hline Total & $57(100)$ & \\
\hline Ethnicity & & $3715(83.9)$ \\
\hline White & $49(84.5)$ & $713(16.1)$ \\
\hline BME & $9(15.5)$ & $4428(100)$ \\
\hline Total & $58(100)$ & \\
\hline Index of multiple deprivation & & $901(19.7)$ \\
\hline 1 (least deprived) & $15(25.4)$ & $867(18.9)$ \\
\hline 2 & $12(20.3)$ & $935(20.4)$ \\
\hline 3 & $13(22.0)$ & $978(21.4)$ \\
\hline 4 & $9(15.2)$ & $896(19.6)$ \\
\hline 5 (most deprived) & $10(16.9)$ & $4577(100)$ \\
\hline Total & $59(100)$ & $757(16.9)$ \\
\hline Left FT education aged <16years & $6(10.3)$ & $3727(83.1)$ \\
\hline Left FT education aged 16years or more & $53(89.7)$ & $4484(100)$ \\
\hline Total & $59(100)$ & \\
\hline BEE blak and minty ethic & & \\
\hline
\end{tabular}

BME, black and minority ethnic group; FT, full time.

and those residents in the least deprived quintile. However, qualitative research aims to be transferable rather than generalisable and the characteristics of women who wrote free-text comments are shown in table 6. Moreover, the findings are consistent with those of other studies and the numbers of women, even in minority groups, are substantial. A further limitation of the quantitative data is that they are entirely based on women's perception and recall of events, which may be inaccurate. However, recall of salient events in childbirth is generally good. ${ }^{3738}$

\section{CONCLUSIONS AND IMPLICATIONS FOR PRACTICE}

These findings reinforce those of other studies stressing the importance of providing reassurance to women in early labour, taking care that women do not feel neglected or dismissed. In particular, young primiparous women and those from minority ethnic groups report greater worry about aspects of early labour than other women and require additional reassurance. While most women who are not contracting strongly and regularly can be reassured that they can safely stay at home, some women labour very rapidly. The Norwegian midwives cited in the study by Eri $e t a l^{19}$ recommended that women come to the hospital to be assessed and to see how their labour progresses. If they are not in active labour, they can then decide for themselves that they would be more comfortable at home and feel confident in going home. ${ }^{19}$ A stand-alone triage unit for women in early labour, separate from the labour ward, would not be influenced by the workload there and could help women to have a more positive experience of early labour. This model may require additional resources to set up, but if it helps women to come to the hospital in active labour, it may save resources overall.

Antenatal education may have a role in improving women's and partners' knowledge and confidence in coping at home but a recent systematic review reported a lack of good evidence as to its effectiveness in promoting good obstetric and psychosocial outcomes more generally. ${ }^{39}$ The maternity services should consider whether women's information needs are being met. 
Table 7 Main themes and examples arising from the qualitative analysis

\begin{tabular}{|c|c|c|}
\hline Themes & Subthemes & Examples \\
\hline $\begin{array}{l}\text { Differentiating } \\
\text { between early and } \\
\text { active labour }\end{array}$ & $\begin{array}{l}\text { 'Rules' about contractions } \\
\text { Behaviour of women in active labour } \\
\text { Having to pretend/exaggerate about } \\
\text { contractions }\end{array}$ & $\begin{array}{l}\text { [...] Called hospital } 9 \text { hours later, told midwife I had urge } \\
\text { to push, still advised to stay home due to contraction } \\
\text { frequency. Felt very uncomfortable, husband called } \\
999, \text { waters broke as soon as ambulance came and } \\
\text { I began pushing at home. Decided to go to hospital } \\
\text { by ambulance, baby born shortly after arrival. [Primip, } \\
\text { IMD1, 25-29years, white] }\end{array}$ \\
\hline Previous labours & $\begin{array}{l}\text { Primiparous women needing reassurance, } \\
\text { being uncertain } \\
\text { Multiparous women having experience, } \\
\text { recognising active labour, being dismissed }\end{array}$ & $\begin{array}{l}\text { When I went into labour with my 3rd child I called the } \\
\text { labour ward and wanted to come into hospital but they } \\
\text { wouldn't let me. I didn't feel like she was listening to me } \\
\text { even though I said I labour quickly. }\end{array}$ \\
\hline $\begin{array}{l}\text { Perceived } \\
\text { consequences for } \\
\text { women }\end{array}$ & $\begin{array}{l}\text { Rushed delivery-insufficient time for } \\
\text { preparation and pain relief } \\
\text { Not a normal birth - instrumental/operative } \\
\text { delivery } \\
\text { Upset-distress, delayed attachment to baby }\end{array}$ & $\begin{array}{l}\text { [... ] Felt unhappy as hadn't had chance for pain relief } \\
\text { option and baby had become distressed. Felt that I } \\
\text { should have been kept in hospital when first went in or } \\
\text { made to feel more welcome on phone. Not the way I } \\
\text { wanted my labour to be and was worrying for me and } \\
\text { my husband. [Primip, IMD1, 25-29years, white] }\end{array}$ \\
\hline
\end{tabular}

VE, vaginal examination.

In summary, most women were not particularly worried about early labour and most of those who contacted a midwife at this time felt that they received appropriate advice. However, some women clearly felt that their care at this time had been poor, suggesting that this is an area where improvements could be made.

Acknowledgements Our particular thanks go to the women who completed the surveys and to Mark Gautrey and staff at the ONS who were responsible for drawing the sample and managing the mailings. The ONS provided data for the sampling frame but bear no responsibility for its analysis and interpretation.

Contributors $\mathrm{JH}$ initiated this study, conducted the analyses and drafted themanuscript. MR was the principal investigator for women's surveys and helpeddirect the analysis. Both authors revised the manuscript.

Funding This paper reports on an independent study which is funded by the Policy Research Programme in the Department of Health. The views expressed are not necessarily those of the Department. The Department of Health was not involved in any aspect of the study.

Competing interests None declared.

Patient consent Detail has been removed from this case description/these case descriptions to ensure anonymity. The editors and reviewers have seen the detailed information available and are satisfied that the information backs up the case the authors are making.

Ethics approval NRES Committee for Yorkshire and The Humber Humber Bridge (REC reference 14/YH/0065).

Provenance and peer review Not commissioned; externally peer reviewed.
Data sharing statement Further analyses of these data are planned so data will not be shared until these are completed.

Open Access This is an Open Access article distributed in accordance with the Creative Commons Attribution Non Commercial (CC BY-NC 4.0) license, which permits others to distribute, remix, adapt, build upon this work non-commercially, and license their derivative works on different terms, provided the original work is properly cited and the use is non-commercial. See: http://creativecommons.org/ licenses/by-nc/4.0/

C Article author(s) (or their employer(s) unless otherwise stated in the text of the article) 2017. All rights reserved. No commercial use is permitted unless otherwise expressly granted.

\section{REFERENCES}

1. National Institute for Health and Care Excellence. Intrapartum care for healthy women and babies. 2014, nice.org.uk/guidance/cg190.

2. Hanada N, Matsuki M, Ota E, et al. Psychosocial and educational interventions in latent phase or early labour for improving birth outcomes (Protocol). Cochrane Db Syst Rev 2015;2.

3. Alehagen $\mathrm{S}$, Wijma B, Lundberg $\mathrm{U}$, et al. Fear, pain and stress hormones during childbirth. J Psychosom Obstet Gynaecol 2005:26:153-65.

4. Hemminki E, Simukka R. The timing of hospital admission and progress of labour. Eur J Obstet Gynecol Reprod Biol 1986;22(12):85-94.

5. Holmes P, Oppenheimer LW, Wen SW. The relationship between cervical dilatation at initial presentation in labour and subsequent intervention. BJOG 2001;108:1120-4.

6. Klein MC, Kelly A, Kaczorowski J, et al. The effect of family physician timing of maternal admission on procedures in labour and maternal and infant morbidity. J Obstet Gynaecol Can 2004;26:641-5. 
7. Bailit JL, Dierker L, Blanchard MH, et al. Outcomes of women presenting in active versus latent phase of spontaneous labor. Obstet Gynecol 2005;105:77-9.

8. Petersen A, Penz SM, Gross MM. Women's perception of the onset of labour and epidural analgesia: a prospective study. Midwifery 2013;29:284-93.

9. Rahnama P, Ziaei S, Faghihzadeh S. Impact of early admission in labor on method of delivery. Int J Gynaecol Obstet 2006;92:217-20.

10. Friedman E. Labor: clinical evaluation and management. 2nd ed. New York: Appleton-Century Crofts, 1978.

11. Cheyne H, Dowding DW, Hundley V. Making the diagnosis of labour: midwives' diagnostic judgement and management decisions. J Adv Nurs 2006;53:625-35.

12. Janssen PA, Desmarais SL. Women's experience with early labour management at home vs. in hospital: a randomised controlled trial. Midwifery 2013;29:190-4.

13. Hodnett ED, Stremler R, Willan AR, et al. Effect on birth outcomes of a formalised approach to care in hospital labour assessment units: international, randomised controlled trial. BMJ 2008;337:a1021.

14. Cheyne H, Hundley V, Dowding D, et al. Effects of algorithm for diagnosis of active labour: cluster randomised trial. $B M$ 2008;337:a2396.

15. Carlsson IM, Hallberg LR, Odberg Pettersson K. Swedish women's experiences of seeking care and being admitted during the latent phase of labour: a grounded theory study. Midwifery 2009;25:172-80.

16. Eri TS, Bondas T, Gross MM, et al. A balancing act in an unknown territory: a metasynthesis of first-time mothers' experiences in early labour. Midwifery 2015;31:e58-e67.

17. Green JM, Spiby H, Hucknall C, et al. Converting policy into care: women's satisfaction with the early labour telephone component of the All Wales Clinical Pathway for Normal Labour. J Adv Nurs 2012;68:2218-28.

18. Cappelletti G, Nespoli A, Fumagalli S, et al. First-time mothers' experiences of early labour in italian maternity care services. Midwifery 2016;34:198-204.

19. Eri TS, Blystad A, Gjengedal E, et al. 'Stay home for as long as possible': midwives' priorities and strategies in communicating with first-time mothers in early labour. Midwifery 2011;27:e286-e292.

20. Spiby H, Walsh D, Green J, et al. Midwives' beliefs and concerns about telephone conversations with women in early labour. Midwifery 2014;30:1036-42.

21. Henderson J, Gao H, Redshaw M. Experiencing maternity care: the care received and perceptions of women from different ethnic groups. BMC Pregnancy Childbirth 2013;13:196.

22. Henderson J, Redshaw M, Labor WA. Worries about labor and birth: a Population-Based study of outcomes for Young Primiparous Women. Birth 2016;43:151-8.

23. Redshaw M, Henderson J. Who is actually asked about their mental health in pregnancy and the postnatal period? findings from a national survey. BMC Psychiatry 2016;16:322.

24. Lindquist A, Kurinczuk JJ, Redshaw M, et al. Experiences, utilisation and outcomes of maternity care in England among women from different socio-economic groups: findings from the 2010 National Maternity Survey. BJOG 2015;122:1610-7.

25. Mander S, Miller YD, safety P. Perceived safety, Quality and Cultural Competency of Maternity Care for culturally and linguistically diverse women in Queensland. J Racial Ethn Health Disparities 2016;3:83-98.

26. Zadoroznyj M, Brodribb WE, Young K, et al. 'I really needed help': What mothers say about their post-birth care in Queensland, Australia. Women Birth 2015;28:246-51.

27. Redshaw M, Henderson J. Safely delivered: a national survey of women's experience of maternity care 2014. Oxford, 2015. https ://www.npeu.ox.ac.uk/reports/807-safely-delivered?highlight=YTo 0OntpOjA7czo2OiJzYWZIbHkiO2k6MTtzOjk6ImRIbGI2ZXJIZCI7aTo yO3M6MTA6lidkZWxpdmVyZWQiO2k6MztzOjE2OiJzYWZlbHk gZGVsaXZlcmVklit9.

28. Redshaw M, Martin C, Rowe R, et al. The Oxford Worries about Labour Scale: women's experience and measurement characteristics of a measure of maternal concern about labour and birth. Psychol Health Med 2009;14:354-66.

29. Garcia J, Evans J, Reshaw M. "is there anything else you would like to tell Us" - Methodological Issues in the Use of Free-Text Comments from Postal Surveys. Qual Quant 2004:38:113-25.

30. Golafshani N. Understanding reliability and validity in qualitative research. Qual Rep 2003;8:597-607.

31. Henderson J, Redshaw M. Change over time in women's views and experiences of maternity care in England, 1995-2014: A comparison using survey data. Midwifery 2017;44:35-40.

32. Redshaw M, Heikkilä K. Ethnic differences in women's worries about labour and birth. Ethn Health 2011;16:213-23.

33. Redshaw M, Miller YD, Hennegan J. Young women's experiences as consumers of maternity care in Queensland. Birth 2014:41:56-63.

34. Brixval CS, Axelsen SF, Thygesen LC, et al. Antenatal education in small classes may increase childbirth self-efficacy: results from a danish randomised trial. Sex Reprod Healthc 2016;10:32-4.

35. Marowitz A. Caring for women in early labor: can we delay admission and meet women's needs? J Midwifery Womens Health 2014;59:645-50.

36. Henderson J, Redshaw M. Women's experience of induction of labor: a mixed methods study. Acta Obstet Gynecol Scand 2013;92:1159-67.

37. Quigley MA, Hockley C, Davidson LL. Agreement between hospital records and maternal recall of mode of delivery: evidence from 12391 deliveries in the UK Millennium Cohort Study. BJOG 2007;114:195-200.

38. Bat-Erdene U, Metcalfe A, McDonald SW, et al. Validation of Canadian mothers' recall of events in labour and delivery with electronic health records. BMC Pregnancy Childbirth 2013;13(Suppl 1):S3.

39. Brixval CS, Axelsen SF, Lauemøller SG, et al. The effect of antenatal education in small classes on obstetric and psycho-social outcomes - a systematic review. Syst Rev 2015;4:20. 